\title{
Implementation of Autonomous Control System of The Chain Wheel Robot Using the Backpropagation Artificial Neural Network (ANN) Methods
}

\author{
Nur Rachman Supadmana Muda ${ }^{1}$, Nugraha Gumilar ${ }^{1}$, R.Djoko Andreas.Navalino ${ }^{2}$,Tirton. ${ }^{1}$, M.Iman Hidayat ${ }^{1}$ \\ ${ }^{1}$ Poltekad Kodiklatad, Batu Indonesia \\ ${ }^{2}$ Defence University,Jakarta, Indonesia
}

\begin{abstract}
The purpose of this research is to implement the Artificial Neural Network (ANN) method in combat robots so it can be directed to shoot targets well. The robot control system uses remote control and autonomous. In the autonomous robot system, ANN back propagation method is applied, where the weight value variable depends on ultrasonic sensor, GPS and camera. The microcontroller system will process automatically depending on the sensor input. Output data is used to direct the robot to the target, tracking and shooting. Robot is used chain wheel systems and weapons that used pistol types. The riffle is mounted on the robot can be moved mechanically azimuth and the elevation towards the target then triggered mechanically by the riffle through the activation of data relays from the microcontroller. Thus, the backpropagation method can be applied to robots so it can be functioned autonomously.
\end{abstract}

Keywords:- Camera, Robot control system, ANN

\section{INTRODUCTION}

Robotics is a manifestation of technological developments implementation that exist at this time, indeed the development of scientific robotics needs to be pursued, especially for those who works in the electronics field [1]. It needs to know and create new innovations regarding robots, can be done by applying various methods both hardware and software. One way to create innovation in robotics is patched Artificial Intelligence (AI) in robot which we designed. Using artificial intelligence, it is expected that the robot control system will be better and can reduce the error value compared to conventional robot control systems [2].

Basically, artificial intelligence can not only be used for control system design, but can also be used for various purposes such as analysis, diagnosis, predicting future based on past data, and etc. Artificial intelligence can be implemented in various fields including electronics, biomedicine, economics, marine, agriculture, geophysics and etc. On robotics field, artificial intelligence has produced many kinds of robots with excellent abilities such as recognizing sound, touch, avoiding obstacles, recognizing patterns or paths through which. In this research, artificial intelligence, namely artificial neural networks, is used to analyze movements or controls in the design of combat robot control systems using Artificial Neural Network methods.

\section{MATERIALS AND METHODS}

\section{A. Materials}

The brushless motor is a moving motor depends on the "PWM" pulse generated from the pulse generator. The speed of the motor depends on the PWM pulse setting [6].

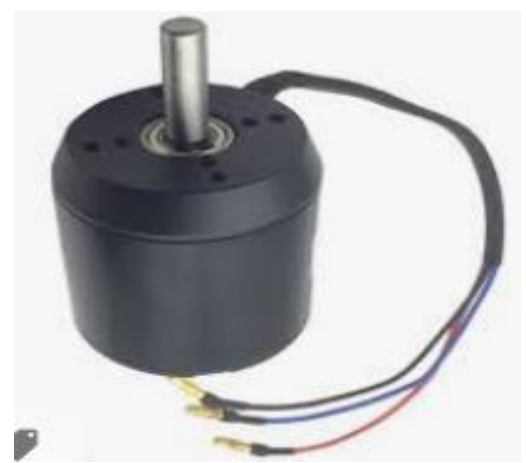

Fig 1:- DC Motor Brushless

This DC motor driver circuit is used to adjust the direction of rotor rotation on DC motor which consists of several electronic components such as transistors and relays.

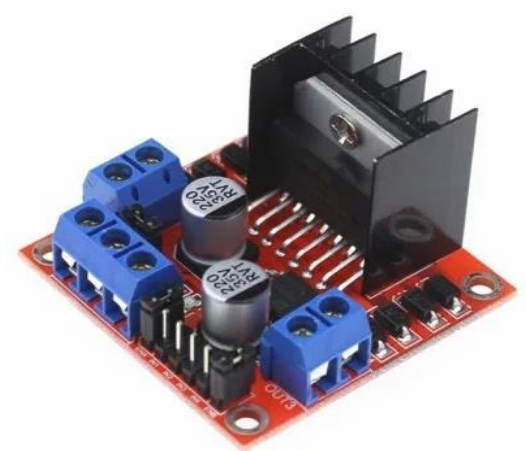

Fig 2:- Driver Motor DC L298

The current is able to be received or gave by very small microcontroller (in milliampere units) so microcontroller can drive a DC motor it requires a series of motor drivers that are capable to flow currents up to several ampere. 
An Arduino Board that uses ATmega 2560 Microcontroller IC. This board has relatively many Pin I / O, 54 digital inputs / outputs, 15 of which can be used as PWM outputs, 16 analog inputs, 4 UART. Arduino Mega 2560 has $16 \mathrm{Mhz}$ crystal [3].

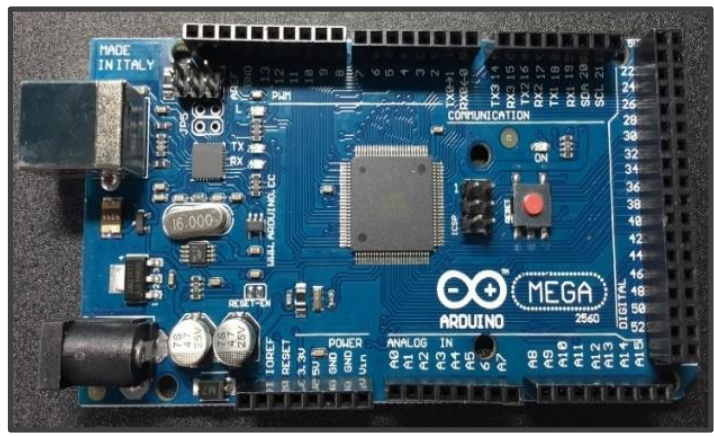

Fig 3:- Arduino Mega

The abbreviation of Arduino IDE is Integrated Development Environment, or in a simple language is an integrated environment that is used for development. It is referred as environment because the software is used to program Arduino to do functions which patched using syntax program. Arduino uses its own programming language which resembles C. The Arduino programming language (Sketch) has been made changing to facilitate beginners in programming from original language. Before being sold to the market, the Arduino microcontroller IC has embedded a program called Bootlader which the functions is as an intermediary between the Arduino compiler and the microcontroller.[3]

MPU-6050 Gyro Sensor 2 + Accelerometer module uses the MPU-6050 which is a small part of the motion processing technology. It combines 3-axis gyroscope and 3axis accelerometer on the same off-silicon stick together with an onboard Digital Motion Processor which is capable to process the complex 9-axis Motion Fusion algorithm, the MPU-6050 is not far off with the problem of cross-axis alignment that can creep in parts separate section [4].

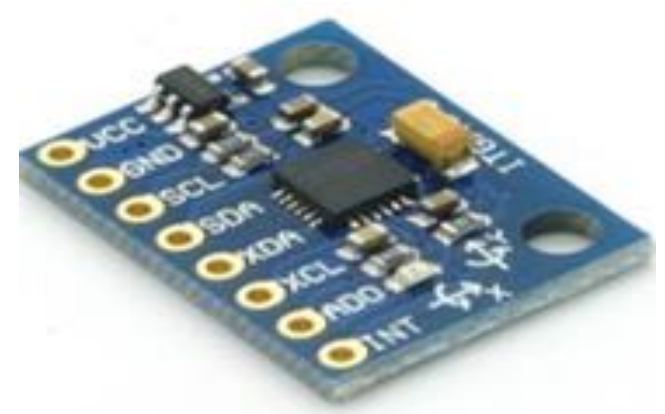

Fig 4:- MPU-6050 Gyro Sensor

\section{B. Methods}

Artificial Neural Network (ANN), or also called simulated neural network (SNN), or generally just called neural network (NN), is a network of small group processing units that are modeled based on human nervous system. ANN is an adaptive system that can change its structure to solve problems based on external or internal information which flows through the network. Because of the ANN characteristic is adaptive, ANN is also often referred as adaptive tissue.[2]

Simply stated, ANN is a non-linear statistical data modeling tool. ANN can be used to model complex relationships between inputs and outputs to find patterns in data. According to a theorem called the "universal estimation theorem", ANN with minimum of hidden layer with a non-linear activation function can model any measurable Boreal function from one dimension to another.

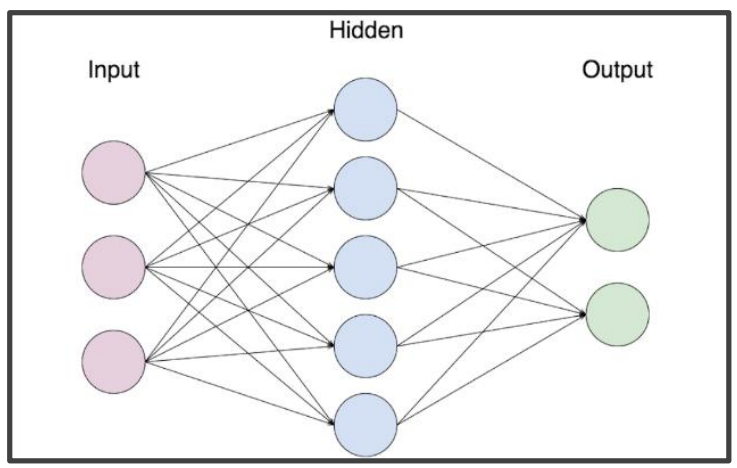

Fig 5:- Model Artificial Neural Network (ANN)

\section{RESULT}

The output block is part of the system tasked with running the system according to the function of the designed equipment, based on the conditions given by the process block. The modeling robot combat based on Artificial Neural Network (ANN) is described as Fig6.

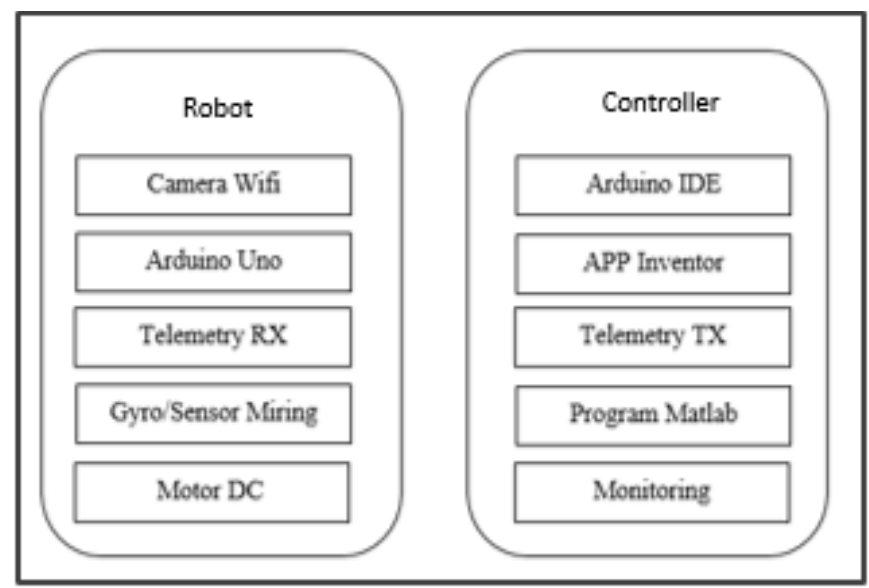

Fig 6:- Module placement chart on robots and controller

To facilitate the reading of the work system of the program to be made or Block diagram on Artificial Neural Network (ANN) combat robot, it will be described as below. 


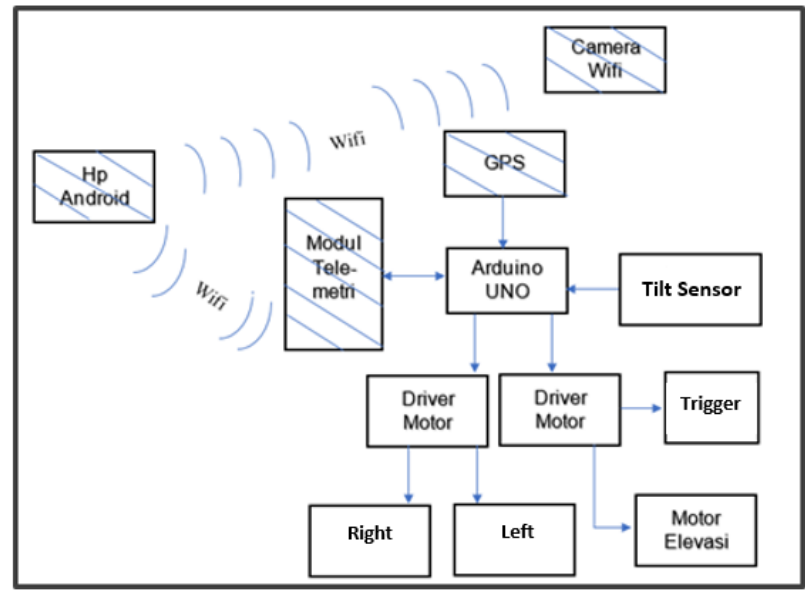

Fig 7:- Data Communication Block Diagram

Figure 7 can be known from the working system of the tool which is as follows:

- Arduino Uno functions as the brain processing data which is received from the wifi module into a command to control combat robots.

- Motor Driver is used to drive the motor and as a current amplifier from Arduino UNO so that it can control the motor.

- Motor Elevation is used to adjust the elevation of the weapon that is moving up and down.

- Trigger motor is used to pull the trigger of a weapon (trigger) so weapons in a city combat car can shoot.

- Right Motor and Left Motor are used to drive the right and left wheels of a city combat car.

- Gradient Sensor/Gyro is used when combat robot deals terrain conditions so at a certain slope the robot moves slightly slow which the combat robot does not reverse.

\section{Robot Control System}

Robot control system is a robot system that is controlled manually and automatically for maneuvering and firing movements as shown in Fig 8 and Fig 9

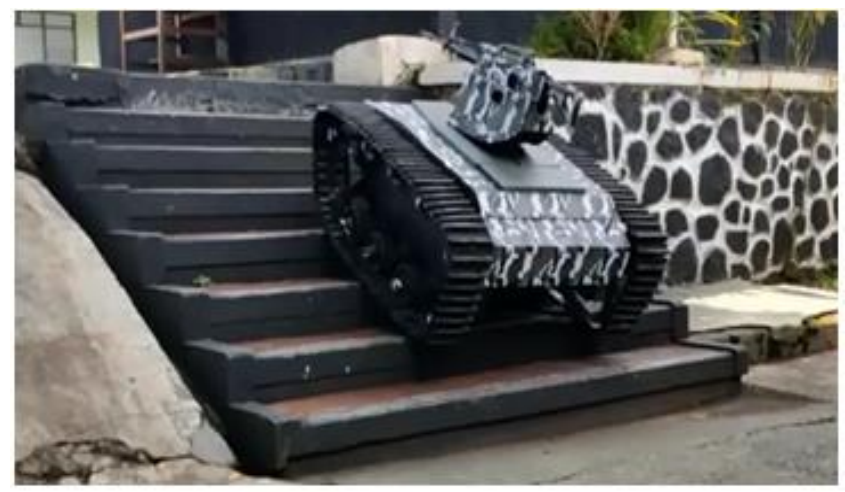

Fig 8:- Maneuver Robot

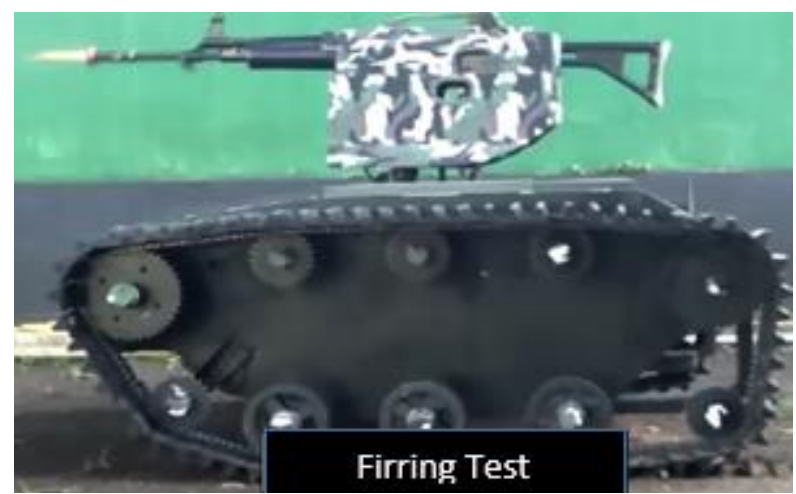

Fig 9:- Firring Robot

\section{Software Planning}

Software design is the design of a programming language that will be included or embedded in an Artificial Neural Network (ANN) combat robot. Software (program language) will be programmed on laptop. As Shown Figure 10 , a software or sender flow diagram is explained in the controller.

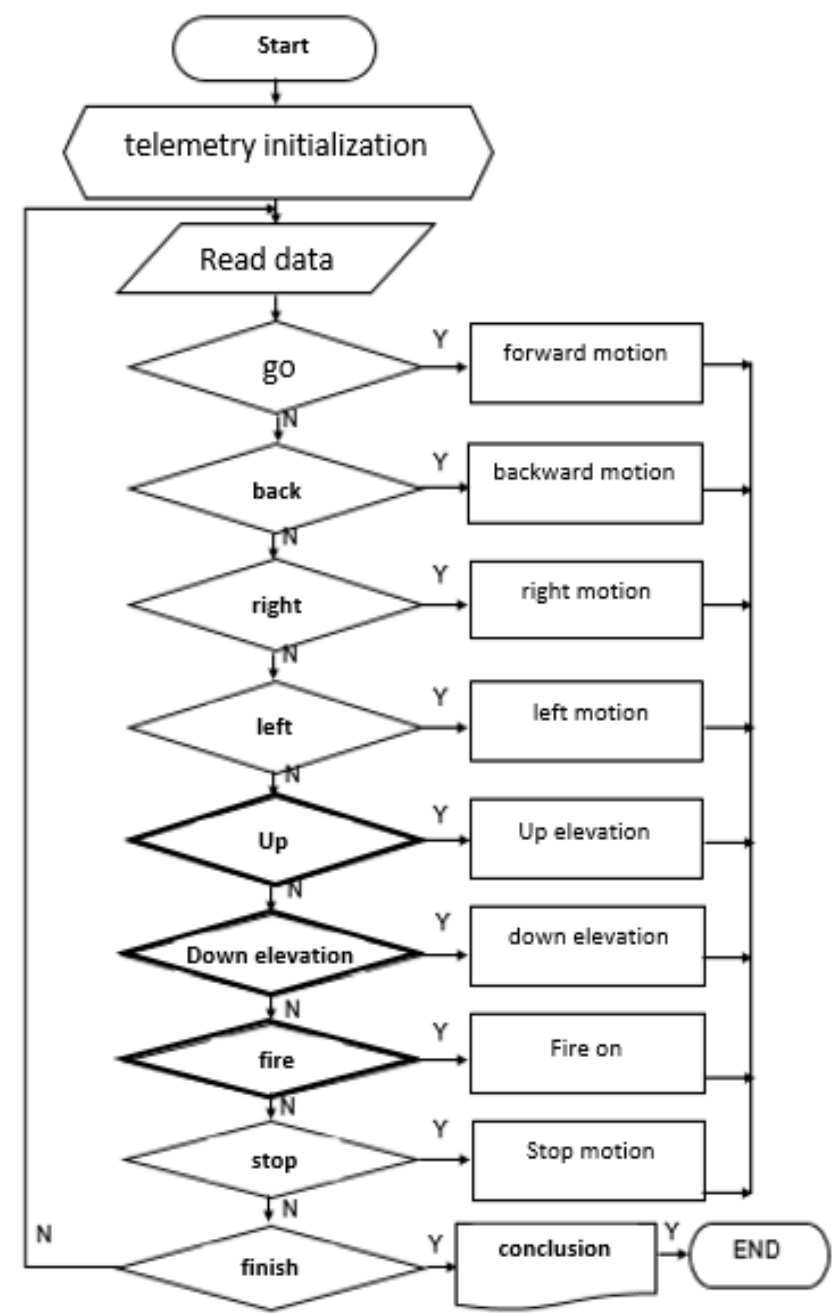

Fig 10:- Flowchart 


\section{RESULT AND ANALYSIS}

\section{A. Result of Arduino Nano and Gyro Testing}

The goals of Arduino nano testing and the gyro testing are determining whether the gyro sensor works well on Arduino nano and measures the position of the robot.

\section{Tool}

The tools which used on test process are written below:

- Laptop/PC

- Arduino IDE Software

- Gyro Sensor

- Arc

- Matlab R2014a Software

\section{Experiment Procedure}

On testing, the experiment steps as follows:

- Arduino circuit and Gyro sensor as a determinant of position sensors. Shown in Fig 11

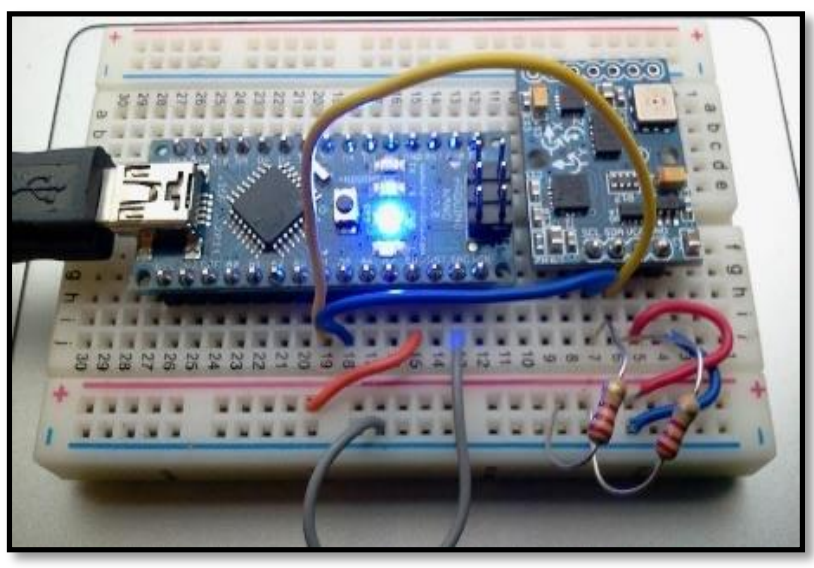

Fig 11:- Arduino dan Gyro picture

- The circuit is placed in the middle of the arc, then connect to the data communication in the Arduino IDE program.

- Determine the position of the gyro sensor in the arc then the value can be seen in the Arduino IDE program in serial monitor.

From the Arduino Uno and gyro testing experiments above, the data is obtained by displaying it on the Arduino IDE programming screen and experimenting until experiment 3 .

\begin{tabular}{|c|c|c|c|c|c|c|}
\hline \multirow{2}{*}{$\begin{array}{c}\text { Angle } \\
\text { detection/position }\end{array}$} & \multicolumn{6}{|c|}{ Value } \\
\hline & Trial 1 & $\begin{array}{c}\text { Error } \\
\%\end{array}$ & Trial 2 & $\begin{array}{c}\text { Error } \\
\%\end{array}$ & Trial 3 & $\begin{array}{c}\text { Error } \\
\%\end{array}$ \\
\hline 1 & 2 & 3 & 4 & 5 & 6 & 7 \\
\hline $180^{\circ}$ & 181.07 & 0.5 & 180.36 & 0.2 & 181.09 & 0.6 \\
\hline $160^{\circ}$ & 160.53 & 0.3 & 160.74 & 0.4 & 161.08 & 0.6 \\
\hline $140^{\circ}$ & 141.17 & 0.8 & 141.20 & 0.8 & 141.09 & 0.7 \\
\hline $120^{\circ}$ & 120.23 & 0.1 & 120.18 & 0.1 & 121.04 & 0.8 \\
\hline $100^{\circ}$ & 100.98 & 0.9 & 100.88 & 0.8 & 100.65 & 0.6 \\
\hline $80^{\circ}$ & 80.43 & 0.5 & 80.99 & 1.2 & 80.36 & 0.4 \\
\hline 1 & 2 & 3 & 4 & 5 & 6 & 7 \\
\hline $60^{\circ}$ & 61.14 & 1.9 & 60.79 & 1.3 & 60.57 & 0.9 \\
\hline $40^{\circ}$ & 40.78 & 1.9 & 40.58 & 1.4 & 40.96 & 2.4 \\
\hline $20^{\circ}$ & 20.69 & 0.05 & 20.17 & 0.8 & 20.27 & 1.3 \\
\hline
\end{tabular}

Table 1:- Arduino test result on Gyro

So it can be formulated by error value:

$=\frac{\text { sensor measurement }- \text { actual measurement }}{\begin{array}{c}\text { actual measurement } \\ \times 100 \%\end{array}}$

$=\frac{181.07-180}{180} \times 100 \%$

$=0.5 \%$
This test is done based on clockwise if the test is done on counter-clockwise then the value that will come minus in the Arduino program. 


\begin{tabular}{|c|c|c|c|}
\hline (2) сомб & - & & \\
\hline $\mid$ & \multicolumn{3}{|c|}{ Senc } \\
\hline \multirow{2}{*}{\multicolumn{4}{|c|}{$\begin{array}{l}181.07 \\
180.36\end{array}$}} \\
\hline \multirow{2}{*}{\multicolumn{4}{|c|}{$\begin{array}{l}180.30 \\
181.09\end{array}$}} \\
\hline & & & \\
\hline \\
\hline \multicolumn{4}{|l|}{181.50} \\
\hline \multicolumn{4}{|l|}{181.52} \\
\hline \multicolumn{4}{|l|}{181.15} \\
\hline \multicolumn{4}{|l|}{181.42} \\
\hline \multicolumn{4}{|l|}{181.61} \\
\hline \multicolumn{4}{|l|}{181.65} \\
\hline & & \\
\hline \multicolumn{4}{|l|}{181.51} \\
\hline$\square$ Autoscroll & No line ending $\checkmark$ & & \\
\hline
\end{tabular}

Fig 12:- Monitor serial picture on 180 degree angle

\section{B. Motor Driver and DC Motor Test}

When testing DC Motor, here is the following steps:

$>$ Arduino circuits, motor drivers and DC motors to control the motor speed as shown in Fig13.

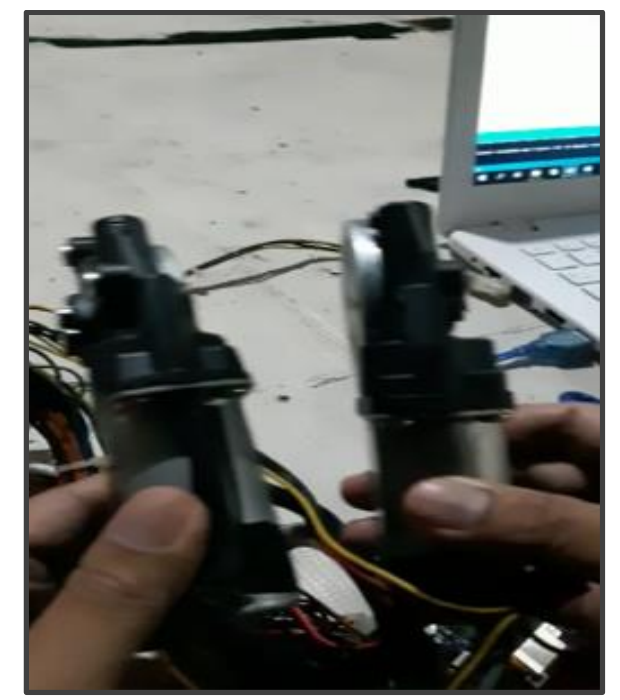

Fig 13:- Arduino, Driver motor and DC motor

Arrange the motor driver and DC motor according to the experiment of Figure 13. Connect with data communication in Arduino IDE programming.

$>$ Set the motor speed and stable the voltage on the specified Arduino pins, then record the results of the experiment as in Table 2.

\begin{tabular}{|c|c|c|c|c|c|c|c|c|c|c|}
\hline \multirow{2}{*}{ No } & PWM & PWM & PIN & PIN & PIN & PIN & \multicolumn{2}{|c|}{ MOTOR 1 } & \multicolumn{2}{|c|}{ MOTOR 2 } \\
\cline { 9 - 12 } & 3 & 5 & 6 & 7 & 8 & 9 & COND & V & COND & V \\
\hline 1 & 255 & 255 & 0 & 0 & 1 & 1 & OFF & - & ON & 98 \\
\hline 2 & 255 & 255 & 0 & 0 & 1 & 1 & OFF & - & ON & 8 \\
\hline 3 & 200 & 200 & 0 & 0 & 1 & 1 & OFF & - & ON & 84 \\
\hline 4 & 175 & 175 & 0 & 0 & 1 & 1 & OFF & - & ON & 78 \\
\hline 5 & 150 & 150 & 0 & 0 & 1 & 1 & OFF & - & ON & 72 \\
\hline 6 & 130 & 130 & 0 & 0 & 1 & 1 & OFF & - & ON & 60 \\
\hline 7 & 255 & 255 & 1 & 1 & 0 & 0 & ON & 98 & OFF & - \\
\hline 8 & 225 & 225 & 1 & 1 & 0 & 0 & ON & 88 & OFF & - \\
\hline 9 & 200 & 200 & 1 & 1 & 0 & 0 & ON & 84 & OFF & - \\
\hline 10 & 175 & 175 & 1 & 1 & 0 & 0 & ON & 78 & OFF & - \\
\hline 11 & 150 & 150 & 1 & 1 & 0 & 0 & ON & 72 & OFF & - \\
\hline 12 & 130 & 130 & 1 & 1 & 0 & 0 & ON & 60 & OFF & - \\
\hline
\end{tabular}

Table 2:- Arduino, Motor Driver, and DC motor tests
From the Arduino testing experiment, the motor and DC motor drivers above enter into Matlab for Learning Process and Prediction Using Bacpropagation Artificial Neural Network (ANN) as learning on DC motor when it's implemented to design of combat robot control systems using artificial neural networks. On this occasion the author made 6 hidden layers and repetitions for learning phase. This can be done if the predicted results produce undesired values, such as same value or very large difference value. Repetition is done by selecting the train toolbox and clicking the train as much as desired.

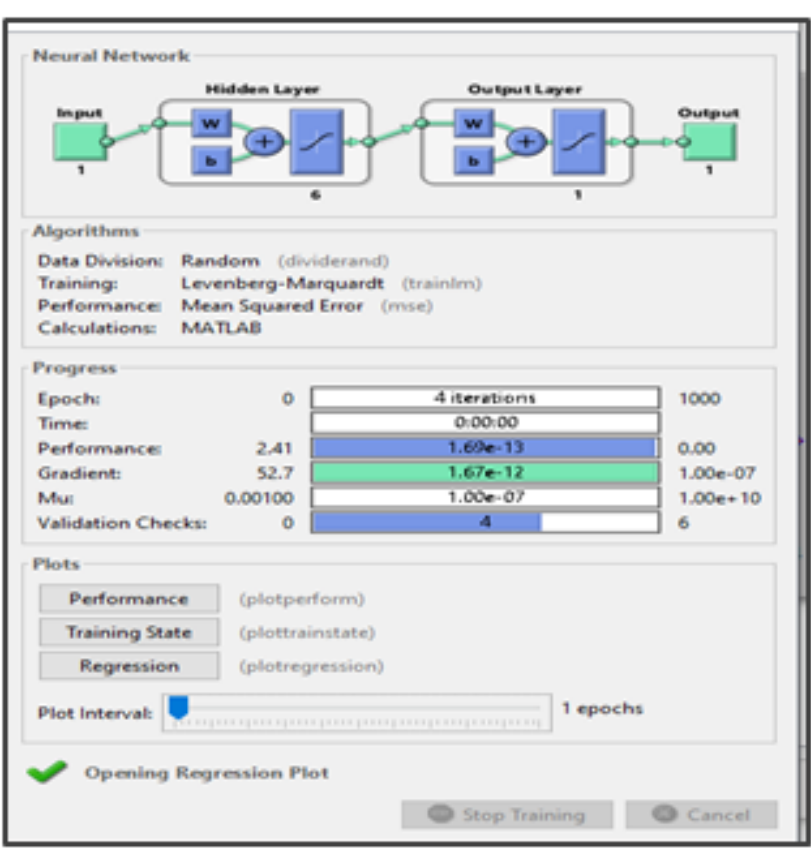

Fig 14 a:- Plan ANN test

As shown in figure $14 \mathrm{a} 14 \mathrm{~b}$ and $14 \mathrm{c}$, the result graph of the test (blue) almost follows from the target graph of training voltage (red). In the earlier data, the test graph shows the adaptation process that will be corrected for the next data. The adaptation process will continue at the beginning of every change of the voltage number. The test results prove that, network training is good enough.

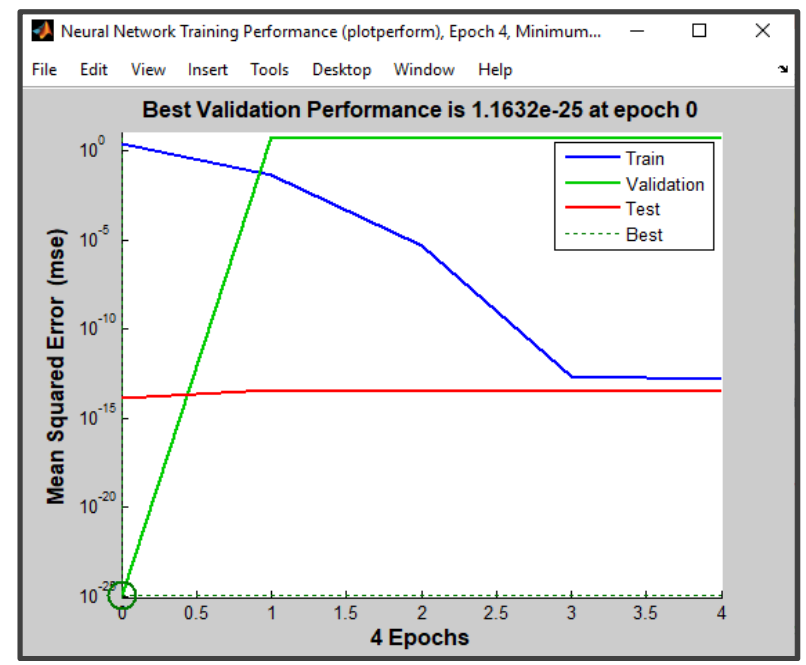

Fig 14.b:- MSE test 


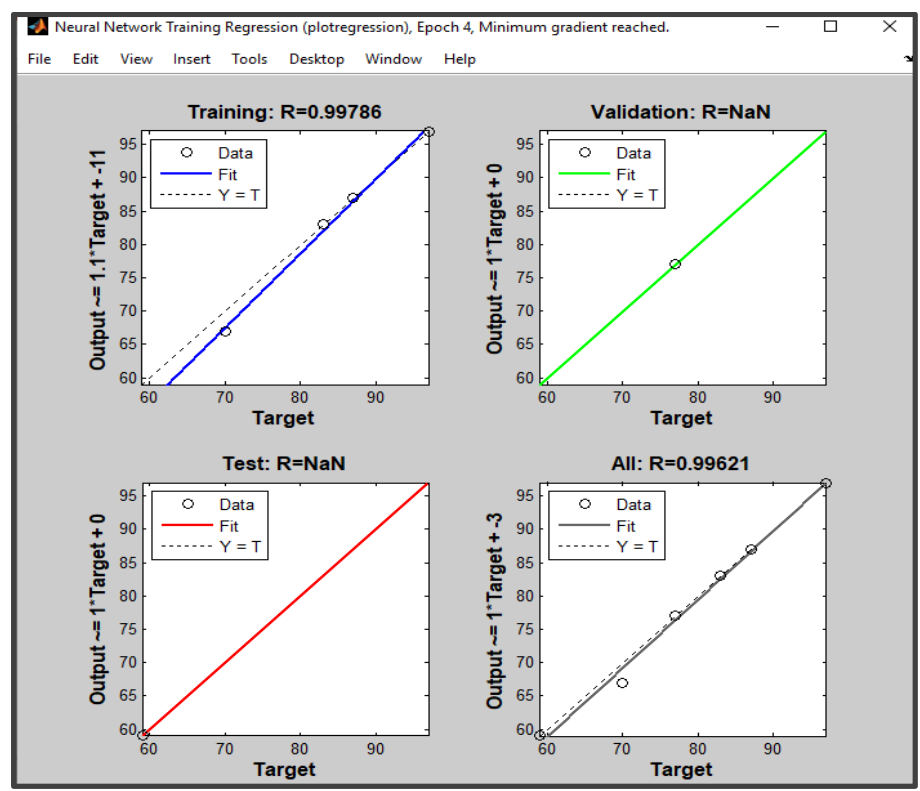

Fig 14 c:- Matlab R2014a Simulink Graph

\section{CONCLUSION}

The results of planning, making and testing applications, then conclusions can be drawn. These conclusions include:

$>$ Robot chain wheel control system can be controlled manually and automatically according to the ANN method with an error approaching $0.5 \%$.

The elevation and firing control system is in accordance with the matlab test data with an accuracy of $0.5 \%$ error.

\section{REFERENCES}

[1]. Et. Karthikrajan, "Multiterrain robotic vehicle with step climbing mechanism," International Journal of Advanced Research in Basic Engineering Sciences and Technology (IJARBEST), volume 3, Special issue 33, march 2017.

[2]. Manav Raj, Robert Seamans "Primer on artificial intelligence and robotics" Journal of Organization Design,2019

[3]. K. M. Merlin Ruby, F. Anne Jenefer, D. Vidhya,"Study of Arduino Controlled Robotic System", International Journal of Innovative Research in Computer and Communication Engineering, Vol. 4, Issue 6, June 2016

[4]. Arif Ainur Rafiq, Wahid Nur Rohman, Sugeng Dwi Riyanto," Development of a Simple and Low-cost Smartphone Gimbal with MPU-6050 Sensor", Journal of Robotics and Control (JRC), Volume 1, Issue 4, July 2020

[5]. Israr Hussain, Rocky Chakma, Shafqat Ali, Imran Ali, "A Microcontroller Based Autonomous Robot For Navigating And Delivering Purpose", Transactions of Nanjing University of Aeronautics and Astronautics . October 2018
[6]. Roni Permana Saputra, Rizqi Andry Ardiansyah, Midriem Mirdanies, Arif Santoso, Aditya Sukma Nugraha, Anwar Muqorobin, Hendri Maja Saputra, Vita Susanti, Estiko Rijanto, "Dc Brushless Motor Control Design And Preliminary Testing For Independent 4-Wheel Drive Rev-11 Robotic Platform", Journal of Mechatronics, Electrical Power, and Vehicular Technology, Vol. 02, No 2, pp 85-94, 2011 